\title{
Apuntes sobre el origen de la autonomía del Ejército en el siglo XIX
}

\author{
Juan Miguel Teijeiro de la Rosa
}

Si aceptamos que autonomía es aquella potestad de que goza una institución para regir sus propios intereses mediante normas y tacultades propias, resulta adecuado aplicar este término a la singular situación en que se halló el Ejército dentro de la estructura jurídico-política de la España del siglo $x \mid x$. $Y$ si convenimos en que un factor determinante para hacer posible la autonomía de cualquier institución es el que se refiere a su ámbito económico, habremos de concluir que el logro de una autarquía decisoria en el área de la gestión de su economia, ayuda a explicar aquella autonomía del Ejército español decimonónico a la que se refería en 1843 el profesor Posada de Herrera cuando decía que el Ministerio de la Guerra era «una nación dentro de otra nación» ".

La consecución de una Administración militar autónoma de la del resto del Estado, y, en concreto, respecto del Ministerio de Hacienda, hasta el punto de escindirse por vez primera de un lado la Administración militar y de otro la Administración Civil, fue el resultado de un largo proceso de reforma que eclosionó en 1828, en las postrimerías del reinado de Fernando $\mathrm{VII}^{2}$. Esta reforma, de carácter administrativo y hacendistico, fue justificada por muchos como necesaria para la debida operatividad de un ejército moderno, al tiempo que criticada por otros que la consideraron un sistema elaborado con el exclusivo fin de conseguir el sometimiento de los empleados que gestionaban la Hacienda militar a la voluntad de los mandos del

«Tiene atribuciones de gobiemo - segia diciendo-, tanto administrativas como de justicia, como económicas; y en una palabra, reúne todas aquéllas que se pueden encontrar en un gobierno centralizado. Los militares son entre nosotros una nación aparte". POSADA DE HERRERA, JOSE, Lecciones de Administración, (1843), Madrid, Edic. INAP, 1978, t. I, págs. 132 y 133.

2 "En el ramo de hacienda tiene (Guerra) bajo sus órdenes a la administración militar o sea Ministerio de Hacienda militar". Ibidem. 
Ejército y, en definitiva, al absoluto control por éstos de los medios económicos presupuestados para el Ministerio de la Guerra.

Fallecido Fernando VII pocos años después de aprobada la reforma a que se acaba de aludir, y asumido por el Ejército liberal su papel de valedor del nuevo régimen que encabezaba la recién jurada Isabel II, fue durante la minoridad de ésta cuando pudieron comenzar a apreciarse las consecuencias inmediatas de la instauración de la nueva Administración militar y a evaluarse sus virtudes y defectos. Este trabajo trata de conseguir una primera aproximación al tema, principalmente desde la óptica de los propios contemporáneos.

\section{LA HACIENDA MILITAR DEL SIGLO XVIII Y SU REFORMA DE $1828^{3}$}

La llegada a España de Felipe $V$ y, con ella, la de las ideas y modos franceses, dio lugar a un afán de racionalización de la Administración que provocó, entre otras cosas, la importación de algunas instituciones del país vecino. De ellas tal vez destaca por su importancia la Intendencia como instrumento de centralización de la gestión económico-administrativa del Estado, y de control por parte de la Corona de los poderes fácticos que distintas autoridades detentaban a lo largo y ancho del territorio nacional. En este sentido los nuevos intendentes, hombres de reconocida capacidad gestora, como lo fueron Patiño, Campillo o el marqués de la Ensenada, se convirtieron en cantera de donde habrian de surgir una parte importante de los secretarios de Estado y altos cargos de la Administración del siglo XVIII y aún de los primeros años del XIX.

Habida cuenta de que el gasto público de la incipiente Administración borbónica iba dirigido en su mayor parte a las atenciones a cargo de la Secretaria de Estado y del Despacho de la Guerra, fue en este ámbito donde desempeñaron principalmente sus misiones los intendentes y todo un entramado de contadores, tesoreros, veedores y comisarios Ordenadores y de Guerra dependientes de aquéllos y agrupados bajo la denominación de Cuerpo Político del Ejército. De esta manera, los intendentes se convirtieron en una especie de "alter ego" de los capitanes generales, en tanto que se les encomendó tener a su cargo y controlar la gestión económica de los recursos del Ejército en cada una de las

\footnotetext{
3 El contenido de este apartado fue objeto de la Tesis doctoral del autor de este trabajo, hoy en trance de publicación bajo el título de La Real Hacienda Militar de Fernando VII.
} 
circunscripciones de aquéllos. Fue así como este equipo de empleados civiles, dependientes de la Secretaría de Estado de Hacienda, pasaron a disponer la ordenación del gasto, las contratas, los pagos, la rendición de cuentas, la fiscalización legal y otros muchos aspectos de la administración militar, con facultades omnímodas en este ámbito.

Como es natural, todo este sistema de Hacienda militar dio lugar a las consiguientes tensiones entre los mandos militares y los miembros del Cuerpo Político, y, en última instancia, entre las propias Secretarías de Guerra y Hacienda. Sin embargo, el pulso entre ambos organismos se fue poco a poco decidiendo a favor de la Secretaría de Guerra, sobre todo como consecuencia de una cierta militarización de la Administración española coincidente con la alarma producida a fines de siglo ante los sucesos revolucionarios que tuvieron por escenario la vecina República francesa. Además, las circunstancias excepcionales que vivió nuestro país durante la guerra de la Independencia facilitaron la natural concentración de poder en los altos mandos militares, y suministraron argumentos a éstos para requerir una autonomía en la gestión de la Hacienda militar que, a su entender, permitiría una mayor eficacia en el funcionamiento de todo el aparato del Ejército. El sistema vigente de administración militar controlado por la Secretaría de Hacienda fue acusado reiteradamente de ser una rémora para la agilidad y operatividad de un Ejército moderno, y sus miembros lo fueron también, en ocasiones, de desidia, desorganización y hasta de malversaciones.

Así las cosas, fueron los propios liberales de Cádiz quienes, necesitados del apoyo de los jefes militares para sus planes de reforma política, optaron por favorecer el robustecimiento de la institución militar, cada vez más profesionalizada y consciente de su propia identidad, a cambio al menos de su neutralidad política. Un Ejército que aceptase la Constitución y las profundas reformas gaditanas, sobre todo en los momentos en que empezaba a emerger en el propio seno de las Cortes una corriente realista que volvía los ojos a las viejas estructuras del Antiguo Régimen, debia ser fortalecido, y mimados sus mandos con la satisfacción de aspiraciones largo tiempo reprimidas. En esta línea, a punto ya de terminarse la guerra, y a propuesta del diputado Canga Argüelles, las Cortes aprobaron el Decreto de 19 de febrero de 1814 que ordenaba que el Cuerpo Político de la Hacienda Militar pasara a depender del Ministerio de la Guerra "sin que en él tenga intervención alguna el Ministerio de Hacienda».

Sin embargo, el regreso de Fernando VII apenas un mes después, y su Decreto de 4 de mayo declarando nulos y de ningún valor los emanados de las Cortes liberales, dejaron sin efecto la asunción por Guerra de las 
competencias sobre los intendentes y demás empleados de la Hacienda militar. De nuevo éstos recuperaron su independencia frente a las autoridades militares y frente al propio Ministerio de la Guerra, y, como no podía ser menos, volvieron a surgir las tensiones y acusaciones entre unos y otros.

Esta situación fue abordada por el Ministro de Hacienda Martín de Garay, quien en 1817 se propuso adoptar un nuevo plan de Hacienda militar partiendo de un previo estudio de las distintas posiciones enfrentadas. Los argumentos de unas y otras los expuso en una Memoria que elevó al Rey el 6 de marzo de 1817. Los que mantenían el criterio de que la administración militar debía desgajarse a todos los efectos del Ministerio de Hacienda aludían a que sólo el de Guerra conocía sus propias necesidades, por lo que un principio de orden y de unidad llevaba a considerar que el pase de la Hacienda militar a este último Ministerio permitiría facilitar la distribución de los caudales públicos y lograr mayores economías. En definitiva, eran siempre razones prácticas y de mejora de la gestión; por otro lado muy cuestionada por las duras críticas que habia sufrido el tradicional sistema de administración militar a la vista de sus pobres resultados tanto en la guerra contra la Convención en tiempos de Carlos IV, como en la guerra de la Independencia. Los argumentos contrarios achacaban la mala gestión de los suministros en aquellas ocasiones precisamente a la dependencia que algunos miembros del Cuerpo Político habían sufrido respecto de los mandos militares, viéndose obligados "a obedecer sin réplica órdenes caprichosas, perjudiciales e injustas por lo común"; pero, sobre todo, hacían hincapié en la necesidad de que el Rey y la nación pudieran tener una garantía en relación con el gasto público más eficaz que la que podia ofrecer una cuenta general presentada a fin de año por el Ministerio de la Guerra al Tribunal de la Contaduría Mayor.

Expuesto todo lo anterior, e inclinándose el Ministro por mantener el control de la Hacienda Militar desde su propio Departamento, consiguió del Rey la aprobación de la Instrucción de Hacienda militar de 6 de marzo de 1818 que confirmaba, e incluso potenciaba, dicho control, haciendo depender del Ministerio de Hacienda lo relativo a nombramientos, destinos y vicisitudes de todos los empleados encargados de gestionar y fiscalizar la Hacienda militar.

Pero de nuevo el futuro de ésta se vio condicionado por los conocidos vaivenes políticos a que liberales y realistas sometieron el azaroso reinado de Fernando VII. Cuando en 1820 el levantamiento de Riego abrió las puertas al Trienio Liberal, otra vez volvió a entrar en vigor la legislación gaditana, y, con ella, el Decreto de 19 de febrero de 1814 que ponia de hecho en manos de Guerra al Cuerpo Político. También ahora los 
doceañistas tenían necesidad de apoyo del Ejército para consolidar su proyecto, que trataba de conseguir un equilibrio político moderado entre las facciones realistas que buscaba la forma de devolver al Rey sus facultades omnímodas de rey absoluto, y los grupos de exaltados veinteañistas que pretendían forzar la máquina revolucionaria. Sin embargo, la brevedad de este interregno liberal, y dificultades de orden administrativo y hasta constitucional, impidieron la culminación de las órdenes e instrucciones que debian regular y hacer efectivo el pase al Ministerio de la Guerra de todo el aparato de la administración económica del Ejército.

En 1823 las tropas francesas, los Cien Mil Hijos de San Luis, repusieron a Fernando VII en el ejercicio pleno de sus poderes absolutos y, como no podía ser menos, éste rechazó todos los actos del gobierno constitucional "de cualquier clase y condición» que fuesen. Una vez más la administración militar volvió a su dependencia tradicional del Ministerio de Hacienda. Es cierto que el ministro de este ramo López Ballesteros, reconociendo la singularidad y características propias de la gestión económica del Ejército y la Marina, acordó, a través de la Instrucción de 12 de enero de 1825, deslindar ésta, administrativa y contablemente, de la restante Administración Civil del Estado; pero, en cualquier caso, manteniendo ambas bajo la jurisdicción y el control del Ministerio de Hacienda y de sus empleados civiles.

Pero no habria de durar mucho este sistema. Las presiones del Ministerio de la Guerra para hacerse con una administración militar autónoma continuaron imparables y, al fin, el entonces ministro del ramo General Zambrano logró que el Rey firmase el Decreto de 31 de mayo de 1828 que daba una nueva organización al Ejército, y en el cual aparecía un artículo del siguiente tenor: "La administración militar queda radicada en el Ministerio de la Guerra, y los empleados de la Hacienda Militar enteramente dependientes y subordinados al mismo Ministerio".

De esta forma conseguía su configuración y dependencia definitiva la antigua Hacienda militar, que ahora iba a ser gestionada e intervenida por el que pasó a llamarse Cuerpo Administrativo del Ejército. Unos empleados que, en su inmensa mayoria, y ya desde hacía décadas, habian perdido la preparación técnica y el prestigio de sus predecesores de buena parte del siglo XVIII, pasaban ahora a administrar y fiscalizar los fondos presupuestados para el Ministerio de la Guerra, bajo las directrices últimas de los mandos militares que durante el siglo xIx tuvieron a su cargo este Departamento, pero, en la práctica, bajo las que en cada caso les fueron impartiendo los jefes militares inmediatos de cada distrito o localidad. El lejano control de la cuenta anual del Ministerio, a cargo de un recién creado 
Tribunal de Cuentas, no fue más que una mera formalidad cumplida casi siempre con muchos años de retraso.

Pocos años llevaban organizados el nuevo sistema de administración militar y el nuevo Cuerpo Administrativo del Ejército cuando falleció Fernando VII. Fue, por tanto, en la década de la minoridad de Isabel II, con las regencias de María Cristina y Espartero (1833-1843), cuando iniciaron realmente su andadura uno y otro. Fue también ésta la época en la que se desarrolló la primera guerra carlista, prueba de fuego importante para la evaluación de esta nueva administración autónoma. Una primera aproximación a los testimonios de los contemporáneos permitirá contrastar si, al menos en aquella primera fase, se cumplieron los objetivos de eficacia y modernidad que sustentaban los que propugnaron la reforma. Permitirá también intuir hasta que nivel se produjo la autonomía económica y hacendística del Ejército, y hasta que punto ambas hicieron posible la autonomía de la institución militar de que se hablaba en un principio, con su consiguiente influencia en los acontecimientos políticos que se sucedieron en España a lo largo del siglo xix.

\section{LA ADMINISTRACIÓN MILITAR EN LA PRIMERA GUERRA CARLISTA}

Entre los meses de octubre de 1833 y julio de 1840 se desarrolló la primera guerra carlista; guerra civil que tuvo por escenario los campos del norte de España, singularmente los de Cataluña, el Maestrazgo, Navarra y el País Vasco, y en la que los contendientes fueron, de una parte el Gobierno de Isabel II, representado por su madre la regente María Cristina, y de otra el infante don Carlos María Isidro con sus partidarios. Una guerra en la que el Ejército regular, y en general el aparato administrativo del Estado, apostaron en favor de la nueva reina, al tiempo que los restos de los desaparecidos Voluntarios Realistas y muchos oficiales separados del Ejército en los últimos tiempos del reinado de Fernando VII, aglutinaron en torno a sí las primeras partidas que poco a poco darían lugar al ejército de don Carlos. Fue una guerra difícil, dado el escenario montañoso en el que se desarrolló, y atípica, porque las operaciones fueron protagonizadas por pequeños grupos guerrilleros o reducidas unidades militares, siendo escasos los despliegues de grandes contingentes en campo abierto.

Estas fueron las circunstancias en las que habia de ponerse a prueba la operatividad del renovado Cuerpo Administrativo del Ejército ante un conflicto bélico, por lo demás limitado. Desde la guerra de la Independencia, y dejando a un lado la casi inexistente confrontación con el ejército 
francés del duque de Angulema en 1823, era la primera vez que la intendencia militar participaba en operaciones logísticas en tiempos de guerra. Sin embargo, frente a algunos elementos coincidentes, como pudiera ser el permanente estado agónico de la Hacienda pública (que terminaría la guerra carlista con una Deuda exterior de 5.875 millones de reales), aparecen otros que permiten apreciar diferencias entre la Administración militar cristina y la Hacienda militar de las Regencias gaditanas. Entre ellas habría que destacar que mientras la propia indole del levantamiento de 1808 produjo una dislocación total de estructuras y del personal de la Hacienda militar, que tardó en poder ser remediada, la Administración del Ejército cristino se vio favorecida por el hecho de que la Administración del Estado permaneció intacta ante el nuevo conflicto, y, al menos en teoría, la cadena de relaciones orgánicas y funcionales entre los centros directivos centrales y los núcleos de operaciones siguió funcionando normalmente. Otro elemento diferenciador que hay que tener en cuenta es que, por primera vez, los miembros de la Administración militar dependían a todos los efectos del Ministerio de la Guerra y de los mandos militares.

En estas condiciones la Administración militar hubo de hacer frente a una movilización del Ejército y fuerzas auxiliares para la cual realmente no se hallaba preparada. Parece que durante la guerra el Ejército liberal llegó a alcanzar una cifra aproximada de 337.000 hombres (incluyendo los cuerpos francos de infantería y caballería, carabineros de costas y fronteras, y las tropas auxiliares inglesas, francesas y portuguesas). Además se movilizó la Milicia nacional en número de 80.000 hombres ${ }^{4}$. "Pronto se conoció que aunque mejorada la organización de la Administración militar, no contaba ésta con los elementos precisos, y sobre todo, con la unidad necesaria a hacer fuerte y eficaz su acción» ${ }^{5}$. De ahí que hubiera de recurrirse a culminar la organización del Cuerpo siguiendo las líneas ya propuestas en el reinado anterior por las propias Intervención e Intendencia generales del Ejército ${ }^{6}$. Estas medidas, sin duda tardías e incompletas, no pudieron evitar que, al menos hasta el año 1838, la desorganización de la

4 PARDo, Ramón, Ideas de Hacienda con demostraciones para la discusión del presupuesto de 1843, comparación de éste con los del tiempo de Fernando VII y consideraciones acerca de las reformas de contribuciones y de las del Culto y Clero, estado actual de las rentas y juicio de la Administración Militar, Madrid, 1843, 40.

s Vicenti Y Gaficia, Juan, Lecciones de Administración militar, Madrid, Imp. de la Administración Militar, 1865, 60.

6 Un Real Decreto orgánico de 17 de julio de 1837 dio una nueva estructura al Cuerpo Administrativo del Ejército, manteniendo su vinculación a Guerra, pero estableciendo nuevos em. pleos y escalas, fijando sueldos, sistema de ingreso, etc. El Decreto reservaba la quinta parte de las vacantes para personal del Ejército, siendo atendidas mediante libre provisión del Gobierno. 
logística del Ejército cristino fuera patente, que la disciplina se resintiera, los suministros dejaran mucho que desear, se hubiera de recurrir con frecuencia a las requisas, se acusara la falta de personal idóneo para los hospitales de campaña, los transportes funcionaran mal y las comunicaciones se vieran destruidas en todas partes ${ }^{7}$.

Christiansen resalta las dificultades de todo tipo por las que se hubo de pasar en los años 1835 y 1836, durante los cuales "la Administración Militar se había derrumbado por la incapacidad del gobierno de pagar a los proveedores". Ello dio lugar a la necesidad de acudir directamente a suministros hechos por los pueblos con cargo a los futuros impuestos debidos al Gobierno central; pero también este recurso terminó haciéndose inviable ante las lógicas resistencias de los pueblos, y desde fines de 1836 "las tropas empezaron a pasar hambre, así como desnudez y enfermedades" ${ }^{8}$. De primera mano son las noticias que suministra Fernández de Córdova, según el cual a principios de 1836 el ministro de la Guerra, Almodóvar, pudo advertir "que la ración del soldado era insuficiente; que raras veces se le daba carne, y que sólo imponiéndolo como multa y castigo a los pueblos rebeldes bebía vino; que las raciones de etapa eran de mala calidad y el peso tan disminuido, que no se comprendía como bastaban para mantenerlo (...). El vestuario era de todo punto deplorable. Muchos cuerpos carecian de capotes. A todos faltaban mantas (...). Otros carecian de ropas de paño, y parecía imposible que la tropa resistiese tantos sufrimientos en medio de uno de los inviernos más rigurosos que habíamos conocido en aquellas provincias". Además de la carencia de subsistencias y suministros faltaba el dinero, "y los oficiales no cobraban sus sueldos, ni el soldado sus reducidas sobras» ${ }^{9}$.

Así las cosas, en 1837, y con el fin de buscar una solución que permitiera la regularización de los suministros a las tropas, se aceptó la propuesta de que la subsistencia de éstas corriera directamente a cargo de la Administración militar. Poco después se hizo cargo del Ministerio de la Guerra el general Isidro Alaix que hasta noviembre de 1839 dirigiría la politica militar. Alaix adoptó soluciones drásticas que le permitieron volcar todos los recursos del pais en apoyo de Ejército cristino, al tiempo que regularizaba los mecanismos administrativos. En consecuencia, las condiciones de

PaRdo, Ramón, o.c., 41.

Christianensen, J., Los origenes del poder militar en España, 1808-1854, Madrid, Aguilar, $1974,81$.

9 Fernandez de Coroova, Fernando, Mis memorias intimas, Madrid, Sucesores de Rivadeneyra, 1886-1889, t. I, 340 y 341 , y t. II, 122. 
las tropas mejoraron sensiblemente, hasta el punto de que "los soldados, cuya miseria se había publicado con frecuencia por sus generales, comenzaron a parecer personas respetables y, algunas veces, ostentosas" 11

Tras apuntar las dificultades que aquejaron a la Administración militar en una guerra contra el Ejército carlista, que en ningún momento llegó a contar con más de 80.000 hombres, cabe preguntarse hasta qué punto derivaron aquéllas de un defecto estructural o de gestión, o bien de otros factores ajenos a quienes tenían a su cargo la misión de apoyar la logística del Ejército liberal.

Por de pronto, los mandos militares trataron de desviar hacia el Gobierno la posible petición de responsabilidades por su aparente ineficacia. A su entender, era la falta de medios en que aquél los tenía sumidos, lo que impedía obtener resultados más brillantes en las campañas ${ }^{12}$. "Por su parte - dice Cepeda Gómez - contraatacaban los ministros desde la prensa gubernamental o desde los escaños de las Cortes acusando a aquéllos de apropiarse el dinero que la Nación les entregaba, o de ineptitud»s 13

Ciertamente, las acusaciones sobre la aplicación incorrecta de los fondos públicos fueron frecuentes. Christiansen piensa que pudo ser cierta la denuncia de malversación de caudales, al menos por parte de algunos que pensaban en la necesidad de reducir el metálico en mano de las tropas porque "los soldados con tanto dinero podrían ser conducidos a cometer excesos" ${ }^{14}$. El mismo Evaristo San Miguel escribía en 1838: «El consumo de raciones que se ha hecho de toda clase en el curso de esta guerra es asombroso. Si se comparase lo distribuido con lo que pertenece en realidad a las plazas de guerra que llevan las armas en la mano, se vería una espantosa diferencia. Los descuidos, las malversaciones, el despilfarro, han sido verdaderamente extraordinarios (...). Las raciones se han distribuido con profusión, se han consumido sin objeto, se han malbaratado, se han vendido a veces por las calles» ${ }^{15}$.

10 Blazouez y Delgado aguilera, Antonio, Historia de la Administración Militar, Madrid, Imp. del Cuerpo Administrativo del Ejército, 1897, pág. 129.

Cristiansen, J., o.c., 101-103.

:2 Herrero Sierra, J.L., El ejército español en el siglo xix, Madrid, Ed. Cuadernos para el Diálogo, Suplemento núm. 64, 1975, pág. 16.

13 CePEDA Gómez, José. El Ejército en la politica española (1787-1843), Madrid, Fundación Universitaria Española, 1990, 207. “Medizábal proclamaba que durante su mandato había enviado grandes cantidades de vituallas y dinero al Ejército, pero también afirmó en las Cortes que los oficiales se gastaban el dinero en el juego o que llevaban el cinturón lleno de monedas de oro, puesto que nada de ellas llegaba a la tropa". ChRISTIANSEN, 0.c., 82.

14 Christiansen, O.C., 84 y 85.

15 [SAN Miguel, Evaristo], "Administración militar", en el periodo mensual redactado por él mismo Revista Militar, t. I. (1838), núm. 7, 400 y 401. 
Diez años más tarde, "un Oficial de Infanteria» recordaba que "sufrieron un espantoso despilfarro las interminables conductas (sic) de numerario que se remesaban a los cuerpos de operaciones, se agotaron los copiosos almacenes surtidos para proveer a todas las necesidades (...). ¡Quién podía resignarse con desprendimiento en las filas a las penurias de la campaña, vestido el oficial con un burdo sobretodo, caminando a pie con zapatos de munición, hambriento como el soldado, reducido a muy escasa ración y privado de ella muchas veces, sin una sola moneda para fumar o lavar la poca ropa en las rápidas expediciones, en medio de la lujosa comodidad de ciertos empleados administrativos, cuando todo faltaba a algunos y todo sobraba a otros". Y culpaba de todo ello a la codicia de los especuladores, a la falta de un escrupuloso control de los suministros y a la transformación de la cuenta y razón en una mera formalidad. A su entender, sólo cuando a partir de 1838 volvió el orden a ésta última se consiguió la regularidad de los suministros y en el percibo de los haberes "que permitian las circunstancias" ${ }^{16}$.

Sin embargo muchas acusaciones recayeron sobre el propio sistema, que habia obligado a la Administración militar "a ejercer su acción devastadora sobre los pueblos", dando lugar a la natural animadversión contra un cuerpo "siempre consumidor y oneroso, nunca reparador por su esencia». En este sentido se entendía que los cargos contra la Administración militar eran injustos, en tanto que venian «inevitablemente provocados por la propia índole de la institución" ${ }^{17}$. No era otro el pensamiento de Evaristo San Miguel cuando en plena guerra decía: "La Administración militar, como hoy está entendida y practicada, es un verdadero caos, fuente de desórdenes, que al fin serán la ruina de la hacienda pública, y una verdadera parálisis de todas las operaciones militares» ${ }^{18}$. En la actualidad Christiansen llega a descalificarla definitivamente al hablar de «su fracaso en la guerra carlista ${ }^{19}$.

No hay que olvidar, finalmente, los argumentos de quienes exculparon a la Administración militar haciendo ver que, al fin y al cabo, no fueron los jefes de ésta, sino los propios mandos de los ejércitos de operaciones quienes, en última instancia, adoptaron con frecuencia medidas drásticas con el

\footnotetext{
16 UN OFICIAL DE INFANTERIA, "De la Administración Militar en sus relaciones con los cuerpos", en La Revista Militar, t. II (1848), 683.

17 Moreno Salamanca, Jacobo, "Rápida ojeada sobre el estado actual de la Administración militar", en La Revista Militar, t. III (1848), 473.

18 [SAN MIGUEL, E.], O.C., 403.

19 Christiansen, O.C., apéndice I, 173.
} 
fin de conseguir aprovisionar a sus hombres. En este sentido cabe decir que en la práctica fueron los propios jefes militares quienes muchas veces ordenaron y dirigieron la política administrativa y logística del Ejército durante la contienda. También, por otro lado, la Administración militar se vio desbordada por la intervención directa de muchos empleados de la Hacienda civil. Un jefe de aquella Administración militar, Ramón Pardo, haria patente tales ingerencias: "los generales y otros gefes militares, tal vez obligados en muchas ocasiones por el imperio de las necesidades se convirtieron no pocas veces en recaudadores y distribuidores de caudales y de efectos; invadieron en el mismo sentido los Intendentes de las provincias las funciones de los gefes de la Hacienda militar de los ejércitos y distritos". A ello había que añadir las amenazas, incluso, de la autoridad militar. La consecuencia - decía - era la imposibilidad de que la Administración militar pudiera cumplir correctamente sus cometidos, por más que sirviese de cabeza de turco a la hora de dirimir responsabilidades. «De ahi el clamoreo contra ella, los dicterios e imposturas de faltas que no cometía; de aquí la opinión de que debería extinguirse por innecesaria» ${ }^{20}$.

También desde el grupo de los militares se reconocería su propia intervención directa en la gestión de la Administración militar, si bien justificándola por las circunstancias de la guerra. En este sentido San Miguel se refería a la necesidad en que se habian visto los generales de acudir a medios extraordinarios para remediar los problemas económicos y de abastecimiento, lo que dio lugar a que muchas veces se hubiera visto en aquéllos "el carácter de opresores (...). Bien sabían estos jefes el mal predicamento en que esto les ponia; mas las necesidades de las tropas hacían indispensablemente nulas todas estas consideraciones. $Y$ lo que unos ejecutaban con todo el aire de dulzura y política, tomaba en otros el carácter de violencia", conductas que eran imitadas también por los jefes de partidas sueltas y comandantes de plazas ${ }^{21}$.

Finalmente, se buscó también una justificación para el Cuerpo Administrativo del Ejército en las carencias presupuestarias que le afectaron al comenzar su andadura, hasta el punto de que entre 1828 y 1836 quedaron sin abonarse atenciones de Guerra por valor de 476 millones

20 Pardo, Ramón, o.c., 41 y 42. Pardo transcribía asi -incluso literalmente- ideas ya expresadas dos años antes por el ministro de la Guerra Pedro Chacón, quien resumía: "Supóngase el sistema de Administración Militar mejor organizado, y digase de buena fe si cabe en la posibilidad que pudiera caminar sin desconcertarse con tantos y tan poderosos elementos de desorden". Exposición sobre el estado actual de las dependencias del Ministerio de la Guerra, Madrid, Imp. Nacional, 1841,42

21 [SAN Miguel, E.], O.C., 402 y 403. 
de reales, y que, sólo entre octubre de 1836 y el mismo mes de 1837, ocurrió lo mismo con otros 336 . Un miembro del Cuerpo dirá que aquella campaña fue llevada a cabo «con escaso personal administrativo (...), sin recursos y sin crédito» 22.

En definitiva, el papel de la Administración militar en esta guerra quedó resumido en la descripción del cargo de Intendente general del Ejército que el mismo autor puso en boca del general Fernández de San Román: «un cargo ilusorio que se reducia, por no tener que administrar, a la correspondencia incesante con el General en Jefe, para multiplicar las páginas del libro de lágrimas, que no de cuentas de su gestión. Bien podía el último soldado considerarse más dichoso y sosegado con sus harapos que aquél tan principal empleado del ejército. Ministro superior de la administración; conducto y ejecutor de las órdenes y encarecimientos, ya del Gobierno, ya del General; blanco forzoso y legal de reclamaciones, súplicas y quejas de Cuerpos y particulares; Jefe para recibir de primera mano todos los sinsabores; súbdito para sufrir el mal humor, las injusticias y las asperezas que las situaciones angustiosas y de difícil salida engendra en los que mandan; tenido por Intendente general, sin ser de hecho más que un humilde habilitado de créditos en papel» ${ }^{23}$.

\section{ADMINISTRACIÓN Y CONTROL FISCAL DEL EJÉRCITO DURANTE LA MINORIDAD DE ISABEL II}

Como se ha repetido insistentemente, la reforma de 1828 había desgajado la Administración militar de la del resto del Estado, haciéndola autónoma. Ello era consecuencia de la aplicación de un principio de "autodeterminación» que dejaba al Ejército parcialmente al margen de los cambios de Gobierno o de ministro. Esta separación de los avatares de la vida política concreta - dice Porras Nadales- dejaba «a salvo los grandes e intocables privilegios en manos del estamento militar: el primero y fundamental, la reserva sacrosanta del presupuesto militar» ${ }^{24}$. En definitiva, era lo mismo que reconocía en 1860 un ilustre hacendista, refiriéndose también a la administración militar: "existe una rama de la administración que tiene una vida propia independiente de la del

22 Blazquez y Delgado agullera, A., o.c., 128 y 129.

23. Ibidem, 128.

24 Porras Nadales, Antonio, “Ordenamiento de la Defensa, poder militar y régimen constitucional en España», en Revista de Estudios Politicos, núm. 35 (1983), 213. 
Estado" 25. Otro profesor se quejaba en estos términos: "Mas para desgracia de la Nación ha sucedido en este ramo (Hacienda) lo que en el de justicia y otros, a saber: que han querido compartir su administración otros ministerios contra su deseada centralización y unidad (...), entre ellos los de Guerra y Marina, introduciendo la administración militar francesa, contraria a nuestro sencillo sistema de Hacienda (...) y haciéndose juez y parte" 26 .

La cuestión ahora es ver como esa dependencia del Cuerpo de Administración del Ejército respecto del Ministerio de la Guerra influyó en su gestión durante aquellos años; y, en concreto, atisbar las dificultades reales con que aquél hubo de encontrarse a la hora de ejercer sus funciones de gestión e intervención de los fondos públicos que la Hacienda del Estado ponía en sus manos.

En primer lugar todos los testimonios coinciden en el hecho de que, una vez conseguida la subordinación de los antiguos miembros de la Hacienda militar al Departamento de Guerra, los militares comenzaron a tratar a aquéllos con una absoluta prepotencia, en la que sin duda jugaba un papel importante la diferencia de estatus social entre una milicia cada vez más consciente de su poder e integrada en una importante proporción, al menos en los puestos más relevantes, por miembros de la aristocracia, y unos empleados administrativos que mantenían su carácter civil, y estaban faltos de una preparación personal adecuada y de un centro o Academia que sirviera para proporcionársela ${ }^{27}$.

Un empleado del Cuerpo Administrativo que ostentaba grado de comisario y ocultó su personalidad bajo las iniciales F.M.M., describió en 1841 con crudeza la situación a que se veían abocados él y sus compañeros. Comparaba la grandeza, brillo y ostentación del mando militar con la representación administrativa "mezquina, sin aparato, sin garantías, dependiente o sirviendo al mismo brazo que quiere limitar, sin más medios para hacerse respetar y obrar con legal independencia que unas cuantas hojas de papel, cuyo contenido, cual si fuera dictado por una estrangera potestad, es siempre mirado con desdén y desprecio, y ni aún por curiosidad se

25 Toledano, Eustaquio, Curso de instituciones de Hacienda Pública de España, Madrid, Imp. de Manuel Galiano, 1859-1860, 2 vols. Reimpresión a cargo del Instituto de Estudios Politicos, Madrid, 1963, t. II, 698.

26 Rios, Juan Miguel de los, Derecho politico general, español y europeo, Madrid, Imp. de don Ignacio Boix, 1845-46, t. II, 165.

27 ArJona y Alvarez, Pedro de, "Administración militar", en Boletin de Administración Militar, núm. 69 (1858), 1. Era un personal «improvisado y sin base alguna de instrucción». FONTANILLES, Joaquin, Ideas generales de Administración militar, Coruña, Iguerete, 1842, 12. 
dignaron leer nunca los que habían de sujetarse a ellas» ${ }^{28}$. El mismo autor decía: «no causarán estrañeza las maneras injustas e indecorosas con que fueron y son tratados ellos (los comisarios) y sus subalternos (...). Los Intendentes de Ejército, se han visto y se ven arrastrados por el mismo torrente; y si bien su superior clase y ordenanza particular, los pone a cubierto de sucesos generales, los han experimentado muy particulares y amargos; y mal habrán podido defender a sus subalternos cuando por sí mismos no alcanzaban sus fuerzas" ${ }^{29}$. Al Cuerpo Administrativo el Ejército "lo tiene por humilde siervo; y le hace pagar bien cara una simple mirada de agrado que alguna vez, y por grandes servicios se ve, como obligado a dirigirle. ¡Tal es el cuerpo administrativo considerado como fiscal e interventor de las necesidades y exigencias del Ejército! ${ }^{30}$. Excúsese la larga cita en aras de lo expresivo del texto. Otros autores corroboraron los mismos hechos. En 1842 uno de ellos reconocía que al Cuerpo «no se le han guardado las consideraciones debidas" ${ }^{31}$. Otro decía pocos años después que "los empleados políticos del ejército carecen de toda tutela, viven huérfanos de todo amparo" ${ }^{32}$. Un tercero hablaba de un cuerpo «injustamente desdeñado" ${ }^{33}$. Tras haber pasado ya treinta años desde la creación de esta nueva Administración militar, otro miembro de la misma seguia quejándose del abandono en que desgraciadamente yacía sumergida» hasta hacía poco ${ }^{34}$. Ya en el presente siglo, el general intendente Narciso Amorós resumía esos difíciles tiempos por los que había pasado la institución, reconociendo que "a la Administración Militar no se la consideraba más que como a un Cuerpo de auxiliares, asimilados, político-militares, empleados muy subalternos al servicio del ejército, cuando no como factores atentos principalmente a hacer granjería de su cargo" ${ }^{35}$.

Pero esta actitud ante quienes tenían encomendada la administración del presupuesto militar incluia, o, mejor aún, tenía como objetivo someter

28 F.M.M., Imposibilidad de la administracion militar en su antiguo y actual estado institutivo, por don (...), Zaragoza, Imp. Nacional, 1841, 11 y 12.

29 Ibidem. 8.

30 Ibidem, 17 y 18. Concluye asi su amarga queja: "La Administración militar es una creación en beneficio del Ejército; él la ha de reconocer así, para tratarla bien, no admitiéndola con disgusto para tratarla mal, como hasta aqui; porque no tener sino siervos para vilipendiarlos y arrollarlos, seria un placer indigno del bravo y virtuoso Ejército español». Ibidem, 29.

3 Fontanilles, J., O.C., 14 y 15.

32 Moreno Salamanca, Jacobo, o.c. 474.

33 HUARTE, Venancio, "Consideraciones sobre la importancia de la Administración militar", en Boletin de Administración Militar, núm. 2 (1858), 1.

34 Arjona y Álvarez, Pedro de, o.c., núm. 68 (1858), 1.

35 Amoros Y VAzQUez Figueroa, Narciso, Intendencia e Intervención, Madrid, Biblioteca iberoamericana de estudios económicos, 1925, 17. 
ésta en cada caso a la voluntad e intereses - no por honestos menos subjetivos o parciales - de quienes pretendian controlar una porción de dicho presupuesto. Ello venía facilitado por un sistema que permitía, o al menos no impedía, el olvido de la debida centralización y unidad de criterios en la ejecución del gasto. Ciertamente la gestión presupuestaria del gasto público dejaba aún mucho que desear desde los puntos de vista hacendístico, administrativo y económico. De hecho hubo de pasar mucho tiempo antes de que el Ministerio de la Guerra pudiera ser considerado como un verdadero centro directivo de aquella actividad, y la realidad es que, en la práctica, tanto los generales inspectores de las diversas armas y cuerpos, como los capitanes generales, y hasta los propios jefes de cada unidad gozaban en la práctica, cada uno en su esfera, de facultades amplísimas a la hora de disponer el gasto ${ }^{36}$.

La independencia que siempre había existido en la administración interior de las unidades se vio así potenciada durante el siglo XIX. Los fondos particulares de cada una de ellas, nacidos las más de las veces con la intención de sus jefes de procurar mejoras materiales en el personal y acuartelamientos a ellos encomendados, fueron moneda común, y dieron lugar a la prohibición contenida en disposiciones como las Circulares de 30 de noviembre y 7 de diciembre de 1849. Vista, por otro lado, la imposibilidad de suprimir definitivamente la práctica viciosa de recibir de los proveedores un porcentaje del importe de las adjudicaciones, la Circular de 5 de octubre de 1850 trató de regularlas limitando éste a un 5 por ciento, obligando a que su importe se controlara por la Junta de jefes y capitanes de cada establecimiento, se aplicara en su totalidad a mejora del rancho y, finalmente, a que se rindieran cuentas del mismo al Ministerio de la Guerra. Excusado es decir que tanto el Ministerio de Hacienda como el Tribunal de Cuentas quedaban totalmente ajenos a estas operaciones ${ }^{37}$.

En este sentido, todas las medidas tendentes a centralizar y modernizar la administración y fiscalización de los suministros chocaron muchas veces con la lógica resistencia de los jefes de cuerpo, que creian ver en ellas una injerencia en su propia gestión y un perjuicio para la eficacia de la misma, que fatalmente recaería sobre el personal a sus órdenes ${ }^{38}$.

36 Busto, Manuel del, El ejército considerado bajo el aspecto político, moral y religioso, Madrid, Imp. de D. Marcos Bueno, 1844, 28 y 29. Habida cuenta de que una de las facultades atribuidas a los inspectores y directores de las armas y cuerpos era precisamente la de dirigir el área económica y administrativa interior de las unidades, es natural que fuese con éstos con quienes, en ocasiones, hubo roces por parte de la Administración militar. FONTANILLES, J., O.C., 39.

37 Raquejo Alonso. Antonio, Historia de la Administración y Fiscalización de las Fuerzas Armadas, Madrid, Ministerio de Defensa, 1922, 73 y 74.

38 Christiansen, J., o.c., 164. 
Toda fiscalización quedaba reducida al formulario pase de «la revista» por parte del comisario de Guerra, a fin de comprobar que las existencias de tropa y semovientes coincidian con las que figuraban en las reclamaciones de devengos que hacía cada unidad, la que, a partir de ahí, obraba con total independencia y sujeta sólo a las órdenes y criterios de sus jefes naturales ${ }^{39}$. Poco podían hacer los empleados de la Administración militar en tal situación, y ante el convencimiento por parte de los jefes militares de que su actitud debía limitarse a una obediencia pasiva al mando ${ }^{40}$. La impotencia debió ser un sentimiento común en muchos de aquéllos ante las exigencias y hasta amenazas de alguna autoridad militar, "amenazas - decía uno de aquellos empleados, ya citado, aludiendo a la primera guerra carlista - contra las cuales no hay poder humano a quien quejarse, porque un General en jefe de un ejército, al hombre a quien se confía la salvación del Estado, difícil es marcarle la tabla de sus derechos" "41.

La situación descrita permite hacer conjeturas sobre las arbitrariedades, e, incluso, ilegalidades que en materia administrativa y financiera pudieron haberse cometido en aquella época en el seno de la institución estudiada. Citaremos un solo testimonio correspondiente ya a los últimos años del reinado de Isabel II: "Han sido muy frecuentes las ocasiones en que se absolvieron faltas de intervención, sobre gastos bien o mal ejecutados; excesos de pagos sin autorización esplícita, ni tan siquiera condicional, y transferencias caprichosas o voluntarias de lo asignado a un capítulo para cubrir atenciones de otro" ${ }^{42}$. Más grave y delicado sería el

39 MORENo LOPEZ, Jacobo, «Examen comparativo de la Administración en tiempos de paz, con la del estado de guerra", en Boletín de Administración Militar, (1870), 144.- J.M.S., Apologia del proyecto de reforma de la administración militar, publicada en Vitoria por el Comisario de Guerra (...). San Sebastián, Imp. de Ignacio Ramón Baroja, II.

40 Fontanilles, J., O.C., 41.

4t PARDO, Ramón, o.c., 41 y 42. «¿Qué son los Intendentes, qué los Comisarios de guerra ante la corte, y en la presencia de un General en gefe? ¿cual es la actitud de estos funcionarios, cuando son llamados por él? Se ha visto a algunos, hasta con dificultad de contestar; y a todos, pendientes de una mirada, de una sonrisa, o de la menor demostración. ¡Bella situación por cierto para ejercer el grave y libre acto fiscal! Generales ha habido con un carácter dulce y considerado, con una sensatez y tino admirables, que han tratado decorosamente a la Administración militar; pero esta es una feliz casualidad; y una institución que depende de ella, vive de merced y está siempre vendida al imperio del más o menos fuerte temperamento de la autoridad militar: asi es, que Intendentes muy dignos y respetables fueron arrollados, amenazados hasta la muerte, sin escasearles las más deprimentes espresiones: Comisarios de guerra muy celosos, empleados muy útiles y de providad, han sido maltratados de obra y palabra (...). A imitación de la primera autoridad del Ejército, han hecho lo mismo, o acaso más, los Generales de división, los gefes de los cuerpos, y hasta los oficiales subalternos se han atrevido con la Hacienda militar de un modo que ruboriza el referirlo (...); no pueden negarse, ni suavizarse: son hechos públicos". F.M.M., o.c., 12 y 13.

42 CORONA Y SERRANO, José, «Examen crítico de la Administración militar", en La Asamblea del Ejército, $2^{a}$ época, t. XV (1867), 7. Christiansen incluye en su obra la siguiente cita de A. Aberdeen: 
estudio - no abordado aún, al menos que sepamos- sobre si hubo o no alguna relación entre la autonomía en la gestión del gasto de que se viene haciendo mención, y la financiación de alguno de los múltiples pronunciamientos que tuvieron lugar durante el siglo XIX. Christiansen, que finaliza su estudio sobre los orígenes del poder militar en España en el año 1854, alude en múltiples ocasiones a sumas de dinero entregadas o prometidas a las tropas en concepto de premios, primas de reenganche, ventajas, etc., por su apoyo o fidelidad a uno u otro jefe: «el dinero se gastaba más en comprar lealtad que eficacia" ${ }^{43}$.

Se ha discutido ampliamente si en el pasado siglo se dio en España una cierta militarización del Estado, o si, más bien, el Ejército fue un mero instrumento en manos de grupos políticos civiles que se sirvieron una y otra vez de él en sus pretensiones de alcanzar el poder. No es éste el lugar para entrar en ese análisis. Pero sí parece, al menos, que, tal y como muestran estudiosos del tema como Seco Serrano y López Ramón, a partir de 1874 se abrió un período durante el cual las Fuerzas Armadas se constituyeron en un poder autónomo dentro del conjunto del Estado, que incluso disputó a éste "competencias sustantivas para la supremacía e independencia del poder civil» ${ }^{44}$.

Pues bien, desde esta perspectiva no cabe duda de que la autonomía conseguida por el Ejército durante el reinado de Fernando VII en el ámbito de la gestión y fiscalización de su presupuesto constituye un lejano pero muy importante precedente en esta línea. De alguna forma la singularidad que los ministerios militares consiguieron respecto de la restante Administración del Estado en materia del control de los fondos que les eran aprobados presupuestariamente, significó un primer paso hacia esa autonomía institucional que paulatinamente se iría perfilando.

Tal singularidad, discutida por algunos y aceptada por los más, llegó a calar tan hondo en el seno de la Administración publica y de las restantes instituciones del Estado, que, bien entrado ya el presente siglo, el propio Romanones hubo de salir al paso para aclarar las ideas y poner las cosas en su sitio. Con motivo de una discusión de presupuestos, y ante la falta

"Los jefes politicos no son aqui jefes politicos, ni los intendentes son intendentes, ni los alcaldes son presidentes de los ayuntamientos. La distribución de los fondos públicos se altera por voluntad del capitán general». O.c., 139. Véase también 84 y 85.

4.3 Cristiansen, C., o.c., 141. Ver también 123, 127, 131, 143 y 150.

44 Seco Serrano, Carlos, Militarismo y civilismo en la España contemporánea, Madrid, Instituto de Estudios Económicos, 1984, 222. LOPEZ RAMÓN. Fernando, La caracterización juridica de las Fuerzas Armadas, Madrid, Centro de Estudios Constitucionales, 1987, 153-155. 
de interés de los diputados por el examen de los del Ministerio de la Guerra, hizo las siguientes precisiones: "Otra causa que ha contribuido a la indiferencia con que el Parlamento acoge el examen de cuanto se refiere al Ejército es que, por una inexplicable aberración, son muchos los que identifican en todos los aspectos, el Ejército con la Patria, y como a la Patria no se la puede discutir, resulta que tampoco debe discutirse al Ejército, el cual por tal modo queda convertido en un ídolo, irresponsable e infalible. $Y$ estos son los peores enemigos de las instituciones armadas; son estos fanáticos los que han contribuido a que el Ejército quede separado del resto del país por temor a que la discusión merme sus prestigios y los respetos que todos le debemos" ${ }^{45}$.

45 Romanones, Conde de, El ejército y la politica. Apuntes sobre la organización militar y el presupuesto de la guerra, Madrid, Renacimiento, 1920, 67. 